\title{
Analysis of Trends in Resistance to Fluoroquinolones and Extended Spectrum Beta-Lactams among Salmonella Typhi Isolates Obtained from Patients at Four Outpatient Clinics in Nairobi County, Kenya
}

\author{
Susan Mutile Kavai ${ }^{*}$, Mourine Kangogo² ${ }^{2}$ Anne W. T. Muigai ${ }^{3}$, Samuel Kariuki ${ }^{4}$ \\ ${ }^{1}$ Institute of Tropical Medicine and Infectious Diseases, Jomo Kenyatta University of Agriculture and Technology, Nairobi, Kenya \\ ${ }^{2}$ Department of Medical Microbiology, Jomo Kenyatta University of Agriculture and Technology, Nairobi, Kenya \\ ${ }^{3}$ Department of Botany, Jomo Kenyatta University of Agriculture and Technology, Nairobi, Kenya \\ ${ }^{4}$ Centre for Microbiology Research, Kenya Medical Research Institute, Nairobi, Kenya \\ Email: *ssnkavai8@gmail.com
}

How to cite this paper: Kavai, S.M., Kangogo, M., Muigai, A.W.T. and Kariuki, S. (2018) Analysis of Trends in Resistance to Fluoroquinolones and Extended Spectrum Beta-Lactams among Salmonella Typhi Isolates Obtained from Patients at Four Outpatient Clinics in Nairobi County, Kenya. Advances in Microbiology, 8, 578-588.

https://doi.org/10.4236/aim.2018.87038

Received: June 4, 2018

Accepted: July 27, 2018

Published: July 30, 2018

Copyright $(0) 2018$ by authors and Scientific Research Publishing Inc. This work is licensed under the Creative Commons Attribution International License (CC BY 4.0).

http://creativecommons.org/licenses/by/4.0/

(c) (i) Open Access

\begin{abstract}
Typhoid fever caused by the bacterium Salmonella enterica serovar Typhi ( $S$. Typhi) causes an estimated 25 million illnesses and approximately 200,000 deaths annually mostly in developing countries. Although the management of typhoid fever has been effectively through antibiotic treatment, $S$. Typhi is increasingly becoming resistant to the currently recommended drugs. This study utilized a quasi-experimental design focusing on archived samples to describe antimicrobial susceptibility patterns of $S$. Typhi and determine the genetic basis of resistance to the two most commonly used classes of antimicrobials. A total sample size of 287 isolates of $S$. Typhi isolates stored in $-80^{\circ} \mathrm{C}$ freezer at the Centre for Microbiology Research was utilized. Isolates were subjected to antimicrobial susceptibility testing to commonly available antimicrobials using disk diffusion method, then analyzed for trends in resistance to fluoroquinolones and extended spectrum beta lactams. Among the 287 isolates 158 (55.5\%) were found to be Multi Drug Resistant (MDR). This implied that these isolates were resistant to all first line classes of treatment such as ampicillin, chloramphenicol and sulfamethoxazole-trimethroprim. In addition to this, these isolates were also resistant to at least one of the currently recommended drugs of choice, either a $\beta$-lactam or a fluoroquinolone. This study observed resistances at $18.2 \%$ and $15.4 \%$ to fluoroquinolones and cephalosporins respectively. PCR results revealed presence of bla $\mathrm{blEM}_{T \text {, }} \mathrm{bla}_{I N T}$ and $\mathrm{bla}_{C T X-M}$ genes coding for resistance to $\beta$-lactams in $80 \%$ of the isolates that had combined resistance to $\beta$-lactams and fluoroquinolones. It is likely that
\end{abstract}


recent heavy use of these classes of antimicrobials is driving resistances to these antimicrobials.

\section{Keywords}

Resistance Trends, Salmonella Typhi, $\beta$-Lactams, Flouroquinolones, Nairobi County, Kenya

\section{Introduction}

Typhoid fever which is a prolonged bacteremic illness with or without diarrhea [1] is caused by the bacteria Salmonella enterica serovar Typhi ( $S$. Typhi). Salmonella Typhi is primarily adapted to humans as the primary host [2]. Typhoid fever is mainly a disease of adults and older children [3] over ten years of age and is commonly spread through the fecal-oral route via food, drinks, and contaminated water. Human carriers can also contaminate water or food and spread to other people through ingestion of the contaminated materials [4], [5].

There is great variation in the clinical course of typhoid fever and this ranges from fever to marked multi-organ system toxaemia [6]. Generally, Typhoid fever is characterized by abdominal pains, sore throat, malaise, nausea, vomiting, weakness, dizziness, and fever. Chronic infection or complicated typhoid infection also sometimes causes confusion [7]. Patients who develop severe disease thereafter range from $10 \%-15 \%[8]$.

In endemic regions, lack of nonspecific features such as diarrhoea, vomiting, or predominantly respiratory symptoms may lead to misdiagnosis of typhoid fever. This is because typically it has an incubation period of 10 - 14 days.

It is also mostly associated with prolonged low-grade fever, headache, malaise, myalgia, dry cough, anorexia, and nausea. In sub-Saharan Africa, the incidence of typhoid fever was estimated at 725 cases/100,000 persons in 2010. However, West and Central Africa lacked studies of incidence data [2] [9].

In a single study in Kibera slums in Kenya, among children 2 to 8 years of age, incidence was estimated at 520 per 100,000 person-years of observation [5]. Multidrug resistant clones of $S$. Typhi are a huge challenge in management of the infection in Kenya. Previous studies recorded a prevalence of $77.2 \%$ multidrug resistant $S$. Typhi isolates collected from hospitals within Nairobi County over the period 1997-2007 [10]. Currently over a third of $S$. Typhi isolates in many endemic areas are multidrug resistant. They equally have diminished susceptibility to fluoroquinolones, which have been the drugs of choice for MDR cases over the last ten years [3]. Other alternative drugs including extended spectrum $\beta$-lactams are also becoming less effective with the growing problem of resistance [11]. The MDR $S$. Typhi is a major problem especially in poor informal settlements in Kenya. In these areas, effective alternative antimicrobials are too expensive to be afforded by majority of the population or else unavailable to the general public [5]. 


\section{Materials and Methods}

\subsection{Bacterial Isolates}

The study utilized a quasi-experimental design analyzing archived isolates from blood and rectal swabs that were obtained from an ongoing surveillance study. The isolates were stored in $-80^{\circ} \mathrm{C}$ freezers located at Centre for Microbiology Research, KEMRI.

A total of 287 isolates were used of which 90 were from Mukurukwa Njenga (MMM), 61 from Mukuru Reuben (MR), 52 from Municipal County Council (MCC), and 84 from Mbagathi District Hospital (MB).

Briefly, the archived vials containing $S$. Typhi isolates were removed from the $-80^{\circ} \mathrm{C}$ freezer and allowed to thaw at room temperature. A loop-full of the isolate was inoculated using the streak plate method on Mac Conkey agar (Oxoid). Incubation was done at $37^{\circ} \mathrm{C}$ for 24 hours. $S$. Typhi was confirmed by serotyping tests using the slide agglutination technique whereby polyvalent antisera $\mathrm{O}$, followed by antisera 9, 12, Vi and d (Murex Diagnostics, Dartford, UK).

\subsection{Antimicrobial Susceptibility Testing}

Antimicrobial susceptibility testing was performed on the isolates using the Kirby-Bauer disc diffusion technique [12]. The inoculum for susceptibility testing was compared against the McFarland 0.5 turbidity standard. E. coli ATCC 25922 and $S$. aureus ATCC 25923 strains were used as the test quality control organisms. Plates were then incubated at $37^{\circ} \mathrm{C}$ for 18 hours. Zones of inhibitions were measured and the interpretation of results was done according to Clinical Laboratory Standard Institute guidelines [13].

\subsection{Polymerase Chain Reaction}

34 isolates that had combined resistance to $\beta$-lactams and fluoroquinolones were further subjected to Polymerase Chain Reaction to detect corresponding resistance genes. Briefly, DNA was extracted from the isolates using the boiling method (10 min boiling, followed by centrifugation $3 \mathrm{~min}$ at 13,000 $\mathrm{xg}$ ). PCR reactions ran for the various resistance genes such as the bla genes for the $\beta$-lactams and PARE genes for the flouroquinolones. The reaction mixture for PCR consisted of pcr beads, $22 \mu \mathrm{l}$ pcr water, $1 \mu \mathrm{l}$ of forward and reverse primer and $1 \mu \mathrm{DNA}$ template. Negative control reaction was used without isolate DNA. Amplification was conducted in $0.2 \mathrm{ml}$ micro centrifuge tube using a programmable Bio-system thermal cycler.

Amplification conditions consisted of 30 cycles of $94^{\circ} \mathrm{C}$ for $30 \mathrm{~s}, 55^{\circ} \mathrm{C}$ for $30 \mathrm{~s}$, and $72^{\circ} \mathrm{C}$ for $30 \mathrm{~s}$, with a final extension step of $72^{\circ} \mathrm{C}$ for $10 \mathrm{~min}$ for the quinolone primers (Table 1). For the ESSBL genes PCR conditions included $5 \mathrm{~min}$ $94^{\circ} \mathrm{C}, 35$ cycles of $60 \mathrm{~s}$ at $94^{\circ} \mathrm{C}, 45 \mathrm{~s}$ at $65^{\circ} \mathrm{C}$ with a $0.5^{\circ} \mathrm{C}$ decrease at each cycle, and $60 \mathrm{~s}$ at $72^{\circ} \mathrm{C}$, final extension at $72^{\circ} \mathrm{C}$ for $7 \mathrm{~min}$. Annealing temperatures differed as indicated on Table 2. 
Table 1. Primers for PCR amplification and sequencing of genes coding for quinolone resistance in the QRDR and plasmid mediated resistance.

\begin{tabular}{cccc}
\hline Primer & Primer sequence & $\begin{array}{c}\text { Annealing } \\
\text { Temps }\left({ }^{\circ} \mathrm{C}\right)\end{array}$ & Expected Bps \\
\hline PARC1 & 5'-ATGAGCGATATGGCAGAGCG-3' & 57 & 412 \\
PARC2 & 5'-TGACCGAGTTCGCTTAACAG-3' & & \\
PARE1 & 5'-GACCGAGCTGTTCCTTGTGG-3' & 55 & 272 \\
PARE2 & 5'-GCGTAACTGCATCGGGTTCA-3' & & \\
\hline
\end{tabular}

Table 2. Nucleotide sequences of PCR primers used to amplify ESBL genes.

\begin{tabular}{cccc}
\hline Primer & Primer sequence & $\begin{array}{c}\text { Annealing } \\
\text { Temps }\left({ }^{\circ} \mathrm{C}\right)\end{array}$ & Expected Bps \\
\hline bla $_{\text {CTX-M }}$ & 5'-SCSATGTGCAGYACCAGTAA-3' & 60 & 593 \\
5'-CCGCRATATGRTTGGTGGTG-3' & & \\
bla $a_{\mathrm{INT}}$ & 5'-GCCCAKCCGACGAACCAGC-3' & 50 & 650 \\
& 5'-ACCTTCAAGATCCCSCTSGC-3' & & \multirow{2}{*}{865} \\
bla $a_{\mathrm{TEM}}$ & 5'-TCGGGGAAATGTGCGCG-3' & 55 & \\
\hline
\end{tabular}

\subsection{Data Analysis}

Data analysis was done using the SAS software, version 9.3 (SAS Institute). Chi-square test was applied for P-value derivation for analysis of patient Metadata and risk factors associated with Typhoid Fever. $(\mathrm{P}<0.05)$ was considered statistically significant. WHO-net program was used to analyze trend for resistance with data presented in bar graphs.

\section{Results}

\subsection{Prevalence of MDR in $S$. Typhi}

In the $287 S$. Typhi utilized in this study, the overall prevalence of MDR was $55.5 \%$. Resistance to fluoroquinolones and $\beta$-lactams was observed at $18.2 \%$ and $15.4 \%$ respectively. 34 isolates had combined resistance to fluoroquinolones and $\beta$-lactams.

\subsection{Selected Meta Data on the Patients with MDR $S$. Typhi}

A total of $11(32.4 \%)$ of these isolates came from female patients while 23 (67.6\%) came from male patients. 21 (61.7\%) of the isolates were obtained from stool samples (Figure 1) while 13 (39.3\%) were obtained from blood samples (Figure 2). Among this 25 (73.5\%) were obtained from patients who had fever at the time they visited the clinic while 9 (26.5\%) tested negative for fever.

$2(18.9 \%)$ of the female patients who had MDR $S$. Typhi had tested positive for HIV at the time of recruitment to the study while 32 (81.8\%) had tested negative. There were more males patients who tested negative for HIV than the females, however there was no male patient who tested positive for HIV in these cohort of patients who had $S$. Typhi that were resistant to the recommended drugs for treatment of Typhoid fever. 
A totalof $15(67.6 \%) S$. Typhi obtained from stool samples were MDR, in addition to being MDR, they also had combined resistance to $\beta$-lactams and fluroquinolones. Most resistance was observed against nalidixic acid (14.4\%) and amoxicillin clavulanate $(13.8 \%)$. Ciprofloxacin and cefpodoxime had the lowest level of resistance at $0.6 \%$ each (Figure 1 ).

Amoxillinclavulanate had the highest resistance level (15.6\%) in patients who $\leq 5$ years of age (Table 3 ). This was closely followed by nalidixic Acid (11.3\%). Nalidixic Acid had the highest resistance level (11.3\%).

Patients in the bracket of 6 - 10 years had S. Typhi that showed highest resistance to nalidixic acid (17.3). This was similar to the patients in the $11-16$ age brackets $(33.3 \%)$.

\subsection{Antimicrobial Profiles for the $S$. Typhi against $\beta$-Lactams and Fluoroquinolones}

The most common resistant phenotype was ampicillin (64.9\%), sulfamethoxazole-trimethroprim (59.6\%), and chloramphenicol, (51.7\%) (Figure 3). Resistance was also observed against nalidixic Acid (16.2\%) and amoxicillin clavaulate $(11.3 \%)$. cephalosporin's' had a low resistance compared to other antimicrobials (Table 4).

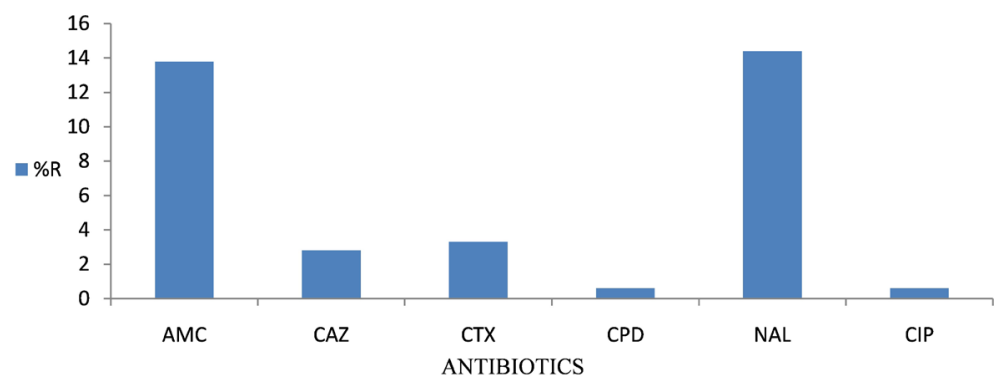

Figure 1. Phenotypic distribution of resistance from isolates obtained from Blood Samples. Resistance levels of isolates obtained from stool samples subjected to phenotypic analysis. The ASTs were against some of the recommended drugs for treatment of Typhoid fever.

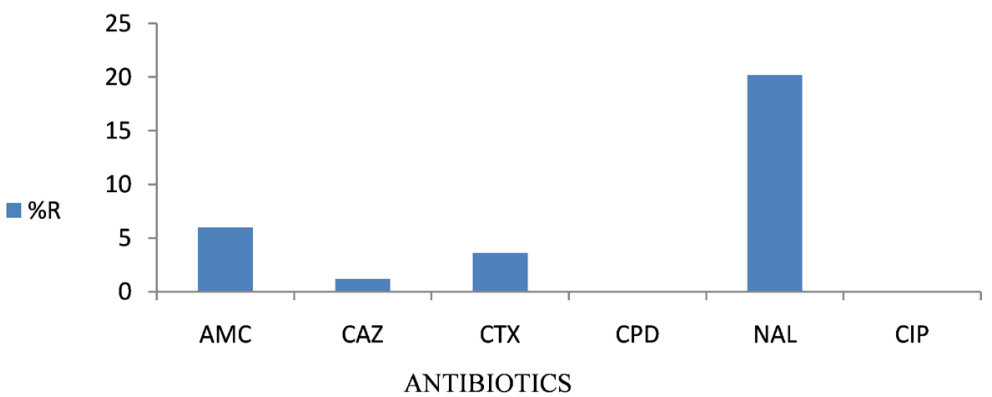

Figure 2. Phenotypic distribution of resistance from isolates obtained from Blood Samples. Resistance levels of isolates obtained from blood samples subjected to phenotypic analysis. The ASTs were against some of the recommended drugs for treatment of Typhoid fever. 


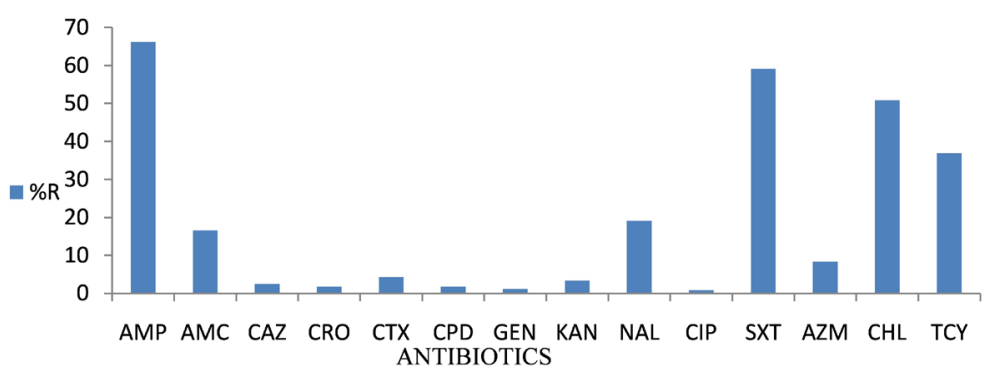

Figure 3. Summary of resistance levels of all the $287 S$. Typhi subjected to a panel of 14 antibiotics. $\mathrm{N}=287$ solates subjected to a panel of 14 selected antibiotics which include Ampicillin (AMP), Amoxicillin Clavulanate (AMC), Ceftazidime (CAZ), Ceftriaxone (CRO), Cefotaxime (CTX), Cefpodoxime (CPD), Gentamicin (CN), Kanamycin (K), Nalidixic Acid (NAL), Ciprofloxacin (CIP), Sulfamethoxazole-trimethroprim (SXT), Azithromycin (AZM), Chloramphenicol (C), and Tetracycline (TCY).

Table 3. Resistance levels against various age distributions.

\begin{tabular}{ccccccccc}
\hline \multirow{2}{*}{ Age } & \multicolumn{4}{c}{$\beta$-Lactams } & \multicolumn{3}{c}{ Fluoroquinolones } \\
\cline { 2 - 8 } & CAZ & CPD & CTX & CRO & AMC & NAL & CIP \\
\hline 5 Years & 3.5 & 0.7 & 2.1 & 1.4 & 15.6 & 11.3 & 0.7 \\
6 - 10 years & 1 & 0 & 4.1 & 1 & 8.2 & 17.3 & 0 \\
11 - 16 years & 0 & 0 & 6.7 & 0 & 3.3 & 33.3 & 0 \\
\hline
\end{tabular}

Resistance levels of MDR $S$. Typhi against recommended drugs of treatment for various age distributions. Ceftazidime (CAZ), Cefpodoxime (CPD), Cefotaxime (CTX), Ceftriaxone(CRO), Amoxicillin Clavulanate (AMC), Nalidixic Acid (NAL), Ciprofloxacin (CIP).

Table 4. Test of association between genders of the Patients and $S$. Typhi that were resistant to $\beta$-lactams and Fluoroquinolones.

\begin{tabular}{|c|c|c|c|c|c|c|}
\hline \multirow{2}{*}{$\begin{array}{c}\mathrm{N}=34 \\
\text { Variables }\end{array}$} & \multicolumn{3}{|c|}{ Chi square } & \multicolumn{3}{|c|}{$\begin{array}{l}\text { Odds Ratio for Gender } \\
\text { (Male/Female) }\end{array}$} \\
\hline & $\begin{array}{c}\text { Value } \\
P=0.05\end{array}$ & $\begin{array}{l}\text { Degrees of } \\
\text { Freedom }\end{array}$ & $\begin{array}{c}\text { Asymptotic } \\
\text { Significance } \\
\text { (2-sided) }\end{array}$ & $\begin{array}{c}\text { Value } \\
P=0.05\end{array}$ & $\begin{array}{l}\text { Upper } \\
95 \% \text { CI }\end{array}$ & $\begin{array}{c}\text { Lower } \\
95 \% \text { CI }\end{array}$ \\
\hline $\begin{array}{l}\text { Gender vs. } \\
\text { Sample }\end{array}$ & $0.359 \mathrm{a}$ & 1 & 0.549 & 0.640 & 0.148 & 2.768 \\
\hline $\begin{array}{l}\text { Gender vs. HIV } \\
\text { Status }\end{array}$ & $4.443 \mathrm{a}$ & 1 & 0.035 & 0.818 & 0.619 & 1.081 \\
\hline $\begin{array}{c}\text { Gender vs. } \\
\text { Malaria status }\end{array}$ & $0.451 \mathrm{a}$ & 1 & 0.970 & 4.86 & 0.100 & 2.356 \\
\hline $\begin{array}{c}\text { Gender vs. } \\
\text { History of Fever }\end{array}$ & $0.818 \mathrm{a}$ & 1 & 0.366 & 0.486 & 0.100 & 2.356 \\
\hline
\end{tabular}

Key: N: Number of valid Cases. CI: Confidence Interval. Tests of associations for various Meta data against gender of the patients who had combined resistance to some of the recommended drugs of choice for treatment of Typhoid fever.

There was no significant association between the Samples the $S$. Typhi were obtained from and the gender of the patients the samples came from in relation to contracting Typhoid fever (Table 1). There also was no significant relation- 
ship between the gender of the patients and their HIV status in relation to Typhoid fever. There was no significant association between the gender of the patients and their malaria status in relation to Typhoid fever. The $\mathrm{P}$ value was > 0.05 indicating that the malaria status of these patients who had resistant strains was not a basis of them having the disease neither was their gender. There was no significant association between the gender of the patients and their Fever status in relation to having Typhoid fever. The $\mathrm{P}$ value was $>0.05$ indicating that the fever status of these patients who had resistant strains was not a basis of them having the disease neither was their gender.

\section{PCR results for selected Resistance genes.}

A total of 27 (80\%) isolates subjected to PCR were found to have resistance genes for both $\beta$-lactams and flouroquinolones. Beta lactamase genes such as $b l a_{\mathrm{TEM}}, b l a_{\mathrm{CTX}-\mathrm{M}}$ and $b l a_{\mathrm{INT}}$ genes were found to be present in isolates numbers such as $54,173,210,191,31,146,114,204,234,225,181$ and 178 (Plate 1(a), Plate 1(b) and Plate 1(c)). PARE and PARC (Plate 1(d) and Plate 1(e)) genes coding for quinolone resistance were also present for most isolates such as 210 , 176, 31, 146, 46, 50, 51, and 299.
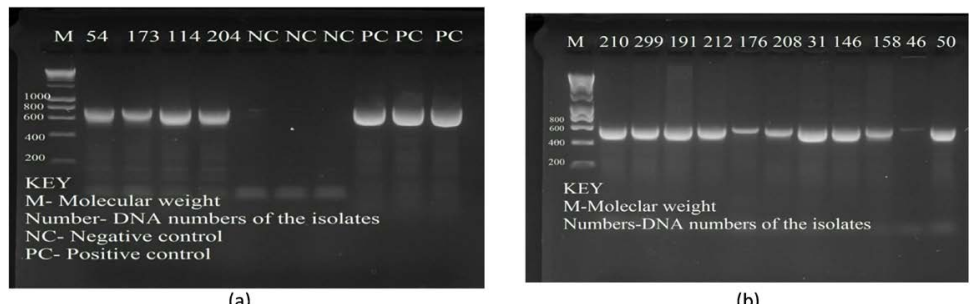

(a)

(b)

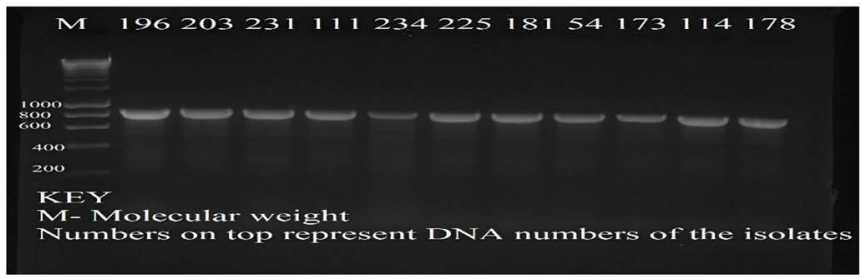

(c)

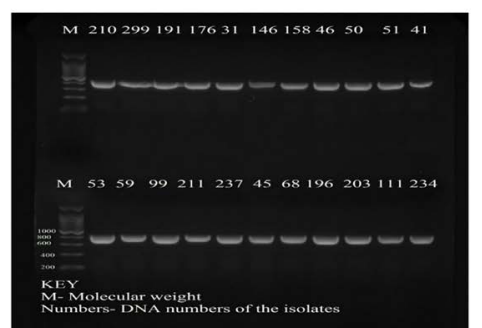

(d)

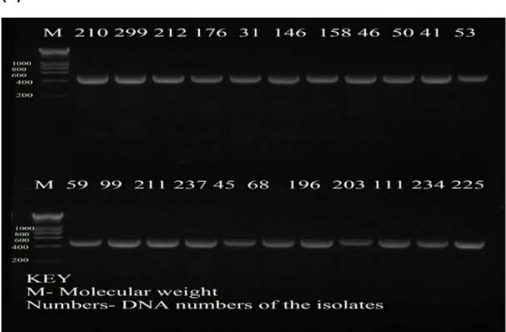

Plate 1. Electrophoresis gel results for blagenes. (a) $b l a_{I N T g e n e} 650 \mathrm{bp}$; (b) $b l a_{\text {CTX-M }}$ $593 \mathrm{bp}$ and (c) $b a_{\mathrm{TEM}} 865 \mathrm{bp}$. M-Molecular weight Ladder; NC-Negative Control (Sterile distilled water); PC-Positive Control (known positive control strains). ${ }^{*}$ Numbers at the top represent DNA numbers of the isolate. Electrophoresis gel results for quinolonegenes. Plates (d) $P A R C_{\text {gene }} 412 \mathrm{bp}$; and (e) PAREgene 272 bp. M-Molecular weight Ladder; NC-Negative Control (Sterile distilled water); PC-Positive Control (known positive control strains). ${ }^{*}$ Numbers at the top represent DNA numbers of the isolate. 


\section{Discussion}

The overall prevalence of MDR $S$. Typhi in this study was 55.5\%. In 1997-1999 a study done in Kenya from hospital isolates found the MDR in $S$. Typhi to be $65 \%$ [14]. While another study carried out in the same study sites in 2010 had the prevalence of MDR $S$. Typhi at $70 \%$ [3]. The prevalence in this study clearly shows a decrease in the MDR $S$. Typhi. Variations in prevalence rates over time can be attributed to environmental, economic and social settings of a community especially the ones involved these studies, including different patterns of antimicrobial use for treatment of typhoid and other endemic bacterial diseases over time.

Characterization of outbreaks caused by MDR $S$. Typhi in Asia and some parts of Africa has been well documented [5] [10]. Typhoid fever outbreaks in Sub-Saharan Africa are rarely documented hence data on prevalence and antimicrobial susceptibility trends are scarce [10].

Therefore the observed MDR $S$. Typhi in Kenya though showing a decrease over time is still something to worry about as $S$. Typhi are multidrug resistant to most of the commonly available antimicrobials.

Data from this study confirms there is rise in resistance in the recommended drugs for Typhoid Fever such as nalidixic acid (16.2\%) and amoxicillin clavulanate (11.3\%). The increased prevalence of MDR $S$. Typhi strains resistant to nalidixic acid should be of public health concern as it is a marker for possible complete fluoroquinolone resistance arising [15].

Resistance was encoded on PARC and PARE genes. In our settings cases of MDR infections are managed using fluoroquinolones, such as ciprofloxacin and norfloxacin. These have been widely used in the last twenty years. Currently, most patients who turned positive for Typhoid fever emerging from slow fever and other symptoms had the clinicians recommend ciprofloxacin as the drug of choice [16].

However with the current MDR prevalence of $S$. Typhi to drugs of choice, it is expected that the resistance to ciprofloxacin would eventually rise if proper measures are not taken to counter resistance [17]. In this study, cephalosporins had a low resistance compared to other antimicrobials. We observed bla $\mathrm{CTX}_{\text {СХ-M }}$, $\mathrm{bla}_{\mathrm{TEM}}, \mathrm{bla}_{\mathrm{INT}}$ which encode resistance to extended spectrum beta lactams.

However for the recommended drugs of treatment for typhoid fever, absolutely no resistance should have been observed. This implies that these drugs could still be effective. In cases where there is uncertainty about the susceptibility of a strain or indeed the diagnosis, it is advisable to select an extended spectrum cephalosporin such as ceftriaxone as the safest choice especially if the patient is admitted to hospital as resistance is currently unlikely [18]. It is important to note that resistance to azithromycin which is another effective oral option for uncomplicated typhoid diseasewas less than $10 \%$. In order to secure its continued effectiveness its use should be prudent for management of typhoid disease [19].

Even in settings in the United States, where Typhoid fever is not endemic, pa- 
tients with similar antibiotic resistance phenotypes show evidence of a longer time to fever clearance and more frequent treatment failure, thus MDR $S$. Typhi is likely to increase overall hospital stay and costs for patients in our settings [20].

\section{Conclusion}

This study observed very high resistance to ampicillin, sulfamethoxazole-trimethroprim, choramphenicol and tetracycline which were the most commonly available antimicrobials in our settings. Resistance was also observed in the $\beta$-lactams especially amoxicillin clavulanate and nalidixic acid. Emerging resistance to nalidixic acid may be a precursor to low level resistance to flouroquinolones, a potentially worrisome situation as this is the current drug of choice for treatment of typhoid fever in Kenya.

\section{Acknowledgements}

SMK is deeply thankful to the Centre of microbiology in Kenya Medical Research Institute for contributing to the workability of her project. She is also appreciative of the staff in Wellcome Trust lab in Centre for microbiology research especially Celestine Wairimu who gave her an ample time as she was doing her lab work.

\section{Author Contributions}

SMK drafted the concept paper of her work and with the help of Prof. SK, Prof. AM and Dr. MK, she came up with a fully baked proposal. Prof. SK who was the first supervisor played a great role in providing consistent guidance and corrections while doing the lab work. Prof. AW and Dr. MK tirelessly corrected her proposal and suggested better ways of beefing it up. Prof. SK and Dr. MK contributed in the manuscript preparation. All Authors contributed to the manuscript by reading it and approving it to finality.

\section{Authors' Information}

SMK nationality is Kenyan. She is a Master student at Institute of tropical medicine and infectious diseases in Jomo Kenyatta University of Agriculture and Technology.

Prof. SK helped in providing massive support from the development of the concept paper to the preparation of the manuscript. Prof. AW is a professor of genetics in Jomo Kenyatta University of agriculture and technology. She assisted greatly in correcting the proposal and manuscript.

Dr. MK is a senior lecturer at the department of Medical Microbiology in Jomo Kenyatta University of Agriculture and Technology. She helped in correcting the proposal and manuscript development.

\section{Ethical Approval}

Approved. 


\section{References}

[1] Baker, S. and Favorov, M. (2010) Searching for the elusive Typhoid Diagnostic. BMC Infectious Diseases, 10, 45-46.

[2] Bhan, M.K., Bahl, R. and Bhatnagar, S. (2005) Typhoid and Paratyphoid Fever. Lancet, 366, 749-762. https://doi.org/10.1016/S0140-6736(05)67181-4

[3] Kariuki S., Revathi, G., Kiiru, J., Mengo, D.M., Mwituria, J. and Muyodi, J. (2010) Typhoid in Kenya Is Associated with a Dominant Multidrug-Resistant Salmonella enterica Serovar Typhi Haplotype That Is Also Widespread in Southeast Asia. Journal of Clinical Microbiology, 48, 2171-2176. https://doi.org/10.1128/JCM.01983-09

[4] Kariuki, S., et al. (2015) Antimicrobial Resistance and Management of Invasive Salmonella Disease. Vaccine, 33, 21-29. https://doi.org/10.1016/j.vaccine.2015.03.102

[5] Breiman, R.F., et al. (2012) Population-Based Incidence of Typhoid Fever in an Urban Informal Settlement and a Rural Area in Kenya: Implications for Typhoid Vaccine Use in Africa. PLoS ONE, 7, e29119.

[6] Kariuki, S., et al. (2010) Typhoid in Kenya Is Associated with a Dominant Multidrug-Resistant Salmonella enterica Serovar Typhi Haplotype That Is Also Widespread in Southeast Asia. Journal of Clinical Mircrobiology, 48, 2171-2176.

[7] Akinyemi, K.O., Smith, S.I. and Oyefolu, A.B. (2005) Multidrug Resistance in Salmonella enterica serovar typhi Isolated from Patients with Typhoid Fever Complications in Lagos, Nigeria. Public Health, 4, 321-327. https://doi.org/10.1016/j.puhe.2004.04.009

[8] Crump, J.A. and Mintz, E.D. (2010) Global Trends in Typhoid and Paratyphoid Fever. Clinical Infectious Diseases, 50, 241-246. https://doi.org/10.1086/649541

[9] Parry, C.M., Wijedoru, L. and Arjyal, A. (2011) The Utility of Diagnostic Tests for Enteric Fever in Endemic Locations. Expert Review of Anti-infective Therapy, 9, 711-725. https://doi.org/10.1586/eri.11.47

[10] Kariuki, S. (2008) Regional Review Article Typhoid Fever in Sub-Saharan Africa: Challenges of Diagnosis and Management of Infections. Journal of Infection in Developing Countries, 2, 443-447. https://doi.org/10.3855/jidc.159

[11] Pham Thanh, D., et al. (2016) A Novel Ciprofloxacin-Resistant Subclade of H58 Salmonella Typhi Is Associated with Fluoroquinolone Treatment Failure. Elife, 5, e14003.

[12] Bauer, A.W., Kirby, W.M., Sherris, J.C. and Turck, M. (1966) Antibiotic Susceptibility Testing by a Standardized Single Disk Method. American Journal of Clinical Pathology, 45, 493-496. https://doi.org/10.1093/ajcp/45.4_ts.493

[13] CLSI (2015) Performance Standards for Antimicrobial Susceptibility Testing; Twenty-Fifth Informational Supplement. CLSI Document M100-S25.

[14] Kariuki, S., Gilks, C., Revathi, G. and Hart, C.A. (2000) Genotypic Analysis of Multidrug-Resistant Salmonella enterica Serovar typhi, Kenya. Emerging Infectious Diseases, 6, 649-651.

[15] Chau T. T., Campbell, J.I., Galindo, C.M., Hoang, N.V.M., Diep, T.S. and Nga, T.T.T. (2007) Antimicrobial Drug Resistance of Salmonella enterica Serovar Typhi in Asia and Molecular Mechanism of Reduced Susceptibility to the Fluoroquinolones. Antimicrobial Agents and Chemotherapy, 51, 4315-4323.

https://doi.org/10.1128/AAC.00294-07 
[16] Parry, C., Wain, J., Chinh, N.T. and Vinh, H. (1998) Quinolone-Resistant Salmonella typhi in Vietnam. Lancet, 351, 1289-1290. https://doi.org/10.1016/S0140-6736(05)79356-9

[17] Parry, C.M., Thuy, C.T., Dongol, S., Karkey, A., Vinh, H., Chinh, N.T., Duy, Nga, P.T., Campbell, T.T., Van Minh Hoang, J.I., Arjyal, N., Bhutta, A., Bhattacharya, Z.A., Agtini, S.K., Dong, M.D., Canh, B., Naheed, D.O., Wain, G.A., Hien, J., Basnyat, T.T. and Ochiai, B. (2010) Suitable Disk Antimicrobial Susceptibility Breakpoints Defining Salmonella enterica Serovar Typhi Isolates with Reduced Susceptibility to Fluoroquinolones. Antimicrobial Agents and Chemotherapy, 54, 5201-5208. https://doi.org/10.1128/AAC.00963-10

[18] Bradford, P.A. (2001) Extended-Spectrum $\beta$-Lactamases in the 21st Century: Characterization, Epidemiology, and Detection of This Important Resistance Threat. Clinical Microbiology Reviews, 14, 933-951.

[19] Galan, J.E. (2016) Typhoid Toxin Provides a Window into Typhoid Fever and the Biology of Salmonella Typhi. Proceedings of National Academy of Sciences of United States of America, 113, 6338-6344.

[20] Bourdan, E. (2016) Typhoid Toxin Provides a Window into Typhoid Fever and the Biology of Salmonella typhi. Proceedings of National Academy of Sciences, 2, 606-635. 